Review

\title{
Equity in Urban Climate Change Adaptation Planning: A Review of Research
}

\author{
Kayleigh Swanson \\ School of Planning, University of Waterloo, Canada; E-Mail: kayleigh.swanson@uwaterloo.ca
}

Submitted: 23 April 2021 | Accepted: 18 June 2021 | Published: 16 December 2021

\begin{abstract}
A growing number of cities are preparing for climate change by developing adaptation plans, but little is known about how these plans and their implementation affect the vulnerability of groups experiencing various forms of underlying social inequity. This review synthesizes research exploring the justice and equity issues inherent in climate change adaptation planning to lay the foundation for critical assessment of climate action plans from an equity perspective. The findings presented illuminate the ways in which inequity in adaptation planning favours certain privileged groups while simultaneously denying representation and resources to marginalized communities. The review reveals the specific ways inequity is experienced by disadvantaged groups in the context of climate change and begins to unpack the relationship between social inequity, vulnerability, and adaptation planning. This information provides the necessary background for future research that examines whether, and to what extent, urban adaptation plans prioritize social vulnerability relative to economic and environmental imperatives.
\end{abstract}

\section{Keywords}

adaptive capacity; climate change adaptation; equity; justice; vulnerability

\section{Issue}

This review is part of the issue "Planning for the Local Impacts of Climate Change: Nobody Left Behind?" edited by Mark Seasons (University of Waterloo, Canada).

(C) 2021 by the author; licensee Cogitatio (Lisbon, Portugal). This review is licensed under a Creative Commons Attribution 4.0 International License (CC BY).

\section{Introduction}

As the impacts of climate change are increasingly being experienced in communities around the world, discussions about climate change adaptation have become the norm in many urban policy settings. A growing number of cities are preparing for the impacts of climate change by developing adaptation plans, but little is known about how these plans and their implementation affect the vulnerability of groups experiencing various forms of underlying social inequity (Anguelovski et al., 2016). As the pace of climate change accelerates, the perceived urgency for the adoption of climate action plans means cities may further relegate social equity considerations relative to environmental and economic imperatives. As cities plan for climate change adaptation, their interventions should reduce the vulnerability of disadvantaged groups by ensuring inclusive planning processes and equitable outcomes. Overlooking social equity concerns in adaptation planning leads to interventions that can reinforce existing trends of socioeconomic vulnerability and create new sources of inequity. Equity and justice are essential components of achieving adequate, fair, and enduring climate action (Klinsky et al., 2017). Accordingly, there is a critical need to examine whether, and to what extent, adaptation planning processes and outcomes are inclusive, equitable, and just.

Adaptation has been variably defined within the climate change context, although responding to vulnerability has emerged as a common theme in the climate justice literature (Hanna et al., 2014; Smit \& Wandel, 2006). Vulnerability refers to the extent to which people and places are susceptible to the adverse effects of climate change and is a function of both exposure and sensitivity to risk (Kelly \& Adger, 2000; Paavola \& Adger, 2006). Vulnerability has both social and physical dimensions: Social vulnerability describes susceptibility based on social, economic, and political factors, while 
physical vulnerability concerns the exposure of people and places to climatic events. Vulnerability is thus a multidimensional concept with connections to population growth, resource depletion, poverty, environmental management, equity, and (in)adequate public policies (Cardona et al., 2012). Vulnerability to specific or multiple environmental stresses ranges in scale from the household or community level to the level of the global population, although practical interventions that reduce vulnerability are most commonly found at the local scale (Smit \& Wandel, 2006). It is closely associated with the concept of adaptive capacity, defined as the ability of an affected system, region, or community to cope with the impacts and risks of climate change (Smit et al., 2001). Climate change adaptation planning - the process through which communities assess their climate vulnerabilities and respond to the risks and opportunities posed by a changing climate (Canadian Institute of Planners, 2011) - is a means of enhancing the adaptive capacity of a community via projects and programs that enable the community's built, natural, and human systems to accommodate climate changes with minimal disruptions. The quality of climate change adaptation planning at the urban level is thus directly related to residents' adaptive capacity.

This review synthesizes research exploring the ways inequities are experienced by disadvantaged groups in the context of climate change. The review provides foundational information regarding climate change impacts in urban areas and the interconnections between underlying forms of social inequity, vulnerability to climate change, and adaptive capacity. This information offers context for research contributions focused on the implications of climate change for urban social equity. Specifically, the reviewed findings provide a baseline for critical assessment of the equity and inclusiveness of urban climate change adaptation planning and inform research that examines whether, and to what extent, adaptation plans prioritize social vulnerability. The relationship between social stratification and exposure to climate risks is well-understood, but the relationship between social inequities and adaptation policy responses is much less clear (van den Berg \& Keenan, 2019). Meaningful inclusion of marginalized groups remains on the periphery of adaptation planning, partly due to weak recognition of disadvantaged groups (Anguelovski et al., 2016). This lack of recognition extends to the identities of these groups (i.e., knowing who the disadvantaged populations are), and their needs and priorities. This issue is tied to the need to develop a more robust understanding of vulnerability, including who is most vulnerable to climate change and in what specific ways.

Studies of vulnerability and disadvantage related to climate change must acknowledge the difference between the effects of climate change, and the effects of policies that address climate change. Both have uneven social impacts, but climate change and climate policy do not necessarily affect the same social groups in the same ways. Assessing the effects of climate change adaptation planning means identifying who gains and who loses from adaptation policy decisions. Previous assessments of this nature have revealed that adaptation actions often reinforce existing inequities and do little to alleviate underlying vulnerabilities (Adger et al., 2005). The unanticipated consequences of climate action planning include urban segregation, spatial inequity, widespread displacement of vulnerable communities, and undesirable land use planning and development interventions. These outcomes are welldocumented (Anguelovski et al., 2016; Long \& Rice, 2019; Sovacool et al., 2015) and it is against this backdrop that the need to improve our understanding of who is truly vulnerable has become clear. This review begins to address these issues by focusing on the relationship between inequity and vulnerability to climate-related stresses and carving out a specific area of equity-focused study within the field of climate change adaptation planning more broadly. The sections that follow describe the effects of climate change on disadvantaged groups and explore forms of inequity in the climate change planning process to provide a comprehensive overview of the equity implications of climate change and the policies and plans designed to help communities adapt to its effects.

\section{Approach}

The objective of this review is to provide a foundation for research that examines climate change planning from an equity perspective. The research findings synthesized in the following sections were gathered during a review of climate justice literature published in English between 2000 and 2020. The review draws on peer-reviewed publications selected from the University of Waterloo library catalogue based on an advanced search of publication titles, keywords, and abstracts using variations of the terms adaptive capacity, urban climate change adaptation, equity, equality, justice, and vulnerability. Studies focused on climate change adaptation planning approaches and outcomes in early adopter cities from the Global North and South were selected to ensure representation of diverse development and geographical contexts and corresponding sources of vulnerability. This approach establishes the relationship between pre-existing social inequity, vulnerability, and climate change adaptation across a range of social and geographic contexts. Literature focused on distributive, procedural, and recognition justice frameworks was also reviewed to explore the justice implications of adaptation interventions. Discussion of the common characteristics used to assess the quality of plans from an equity perspective was informed by a review of plan quality research to draw conclusions about the current state of adaptation planning in the context of equity. The findings presented are part of a broader effort to better 
understand the relationship between social inequity, vulnerability, and adaptation policy responses.

\section{The Relationship Between Climate Change and Social Inequity}

Devising effective adaptation interventions requires a robust understanding of the interconnections between climate change, social inequity, vulnerability, and adaptive capacity. This means climate change adaptation planning must first and foremost consider the relationship between climate change and social inequity, specifically the ways individuals and communities are differently exposed to climate change impacts depending on factors such as income, education, race, ethnicity, gender, age, and (dis)ability. Studies of vulnerability in the context of climate change have repeatedly found that disadvantaged groups experiencing initial social inequity are disproportionately affected by climate change, resulting in greater subsequent inequity (Islam \& Winkel, 2017; Thomas et al., 2018). Social inequity is multidimensional and variably refers to inequities based on demographic characteristics, inequities regarding assets and income, and inequities regarding political power and access to public resources. In the context of climate change, inequity is part of the discussion of climate justice, which is situated within the broader environmental justice movement. Climate justice discourse overlaps with, and expands, more traditional environmental justice concerns by focusing on vulnerabilities and community resilience (Schlosberg, 2013). Barnett (2006) identifies five key assumptions of the climate justice agenda which are unpacked in the remainder of this review: 1) the responsibility for climate change is not equally distributed; 2) climate change will not affect all people equally with some people and groups more vulnerable; 3 ) this vulnerability is determined by political-economic processes that benefit some people more than others; 4) climate change will compound under-development; and 5) climate change policies may themselves create unfair outcomes by exacerbating, maintaining, or ignoring inequities. These central claims of the climate justice debate, especially those related to the distribution of vulnerability and impacts, are inextricably intertwined.

Much of the existing research on climate justice has focused primarily on the debate over differences between countries in terms of their responsibility for causing climate change and their consequent responsibility for carrying out mitigation and adaptation activities (Islam \& Winkel, 2017). It is well-understood that the countries that have contributed least to climate change will be the ones most impacted by its effects (Bathiany et al., 2018), leading to demands for redistribution efforts by those least affected and most responsible (Steele et al., 2012). In addition to addressing between-country inequities, the climate justice debate requires us to consider the relationship between climate change and within-country inequity. The follow- ing sections explore this relationship by highlighting the main channels through which the inequity-aggravating effects of climate change materialize at the urban level and describing some of the resulting local inequities that exist between areas occupied by elite versus poor urban populations.

\subsection{Defining Disadvantage}

In this review, disadvantaged populations are understood as those for whom underlying social inequityand corresponding reduced adaptive capacity-causes disproportionate suffering from the adverse effects of climate change. The differential impacts of climate change on various populations are well-understood given considerable evidence suggesting that socially and economically disadvantaged people suffer disproportionately from climate impacts (Adger et al., 2005; Intergovernmental Panel on Climate Change, 2014; Jerneck \& Olsson, 2008; Steele et al., 2012; United Nations Human Settlements Program, 2011). Differentiation in demographic variables such as age, gender, (dis)ability, ethnicity, education, and health are often cited as being related to both vulnerability and the ability to cope with risk (Islam \& Winkel, 2017; Smit et al., 2001). Those who are unable to cope with injuries and illnesses caused by the impacts of climate changeespecially children and the elderly-are also at considerable risk of being adversely affected (Davoudi et al., 2009). Previous incidents have demonstrated this reality: Most of the lives claimed by the European heat wave (2003) and Superstorm Sandy (2012) were among the poor and isolated elderly (Davoudi et al., 2009; Kunz et al., 2013), while the aftermath of Hurricane Katrina (2005) reminds us that climate events first and foremost affect economically disadvantaged populations and communities of colour (Byrnes, 2014; Schrock et al., 2015). Similar patterns of vulnerability have been documented in the Global South among women and people living in poverty (Islam \& Winkel, 2017).

\subsection{Climate Change and Local Inequities}

There are three main channels through which the inequity-aggravating effects of climate change materialize: 1) increased exposure of disadvantaged groups to the adverse effects of climate change; 2) increased susceptibility to the damage caused by climate change among these groups; and 3) decreased ability for disadvantaged groups to cope and recover from the damage suffered. These conditions can compound individual characteristics (such as gender, age, and (dis)ability) as well as underlying forms of social marginalization (such as ethnic and racial exclusion) to create considerable vulnerability among already disadvantaged groups (Shi et al., 2016). Conversely, the inequity-aggravating effects of climate change favour more socially advantaged populations who are better prepared to respond to increased 
stress from climate risks. Just as the ability to lessen one's ecological footprint is determined by education, income, and access to green infrastructure, the ability to live a climate-resilient lifestyle also depends on socioeconomic variables that determine one's ability to move to a safer area, ensure their assets, and gain access to amenities, services, and social protection (Davoudi et al., 2009; Hallegatte et al., 2018; Long \& Rice, 2019). In Rio de Janeiro, Brazil, for example, poverty coupled with the lack of secure land tenure for a notable portion of the city's population make poor neighbourhoods especially vulnerable to climate change impacts that are expected to increase in severity. While these highly vulnerable sub-populations occupy low-income informal settlement areas near waterways where they are at considerable risk, relatively less vulnerable upper-class residents live in high-rise apartment buildings located in areas less susceptible to inundation (Blake et al., 2011).

In this context, the urban population can be divided into categories of the urban elite, who have the political influence and financial stability to insulate themselves from climate change, and the urban poor, who find themselves lacking the capacity to reduce the direct and indirect impacts of climate change (Davoudi et al., 2009; Long \& Rice, 2019). This division of the urban population has visible implications for planning: There are notable differences between the areas occupied by the climateresilient elite and those that are home to the climate vulnerable poor (as the Rio de Janeiro case demonstrates). Lower-income groups with reduced access to city services and amenities tend to be more susceptible to natural environmental threats and climate risks, and recent studies have demonstrated that poorer urban neighbourhoods experience slower response times and less adequate emergency services during environmental disasters (Anguelovski et al., 2016; Graif, 2016; Wamsler et al., 2013). On the other hand, the climate-resilient lifestyle of the urban elite carries the security of living in insulated areas that are less susceptible to climate risks (Long \& Rice, 2019). Findings from Hallegatte and Rozenberg (2017) confirm that lower-income groups may be seriously affected by climate change even when impacts on the rest of the population are limited. In the context of limited financial resources and increased stress from climate change, socioeconomic status becomes an important determinant of vulnerability and access to services.

\section{Understanding Disadvantage and Injustice}

The justice and inclusivity of adaptation interventions largely depends on how planning actors define and measure vulnerability and disadvantage in a certain context. As such, gaps and shortcomings in our understanding of who is truly vulnerable to climate change can lead to adaptation plans and interventions that aggravate rather than reduce inequity (van den Berg \& Keenan, 2019). Scholars have developed various categories and typologies for identifying disadvantaged populations in the con- text of climate change, many of which relate to how certain groups experience injustice in the process and outcomes of adaptation planning.

\subsection{Acts of Commission and Omission}

Anguelovski et al. (2016) categorize urban adaptation injustices as either acts of commission or acts of omission. Injustices of commission refer to adaptation interventions-such as infrastructure investments, land use regulations, or the establishment of newly protected areas-that disproportionately affect or displace poor and marginalized residents. Informal settlements in Global South cities often experience injustices of commission as governments faced with climate change engage in adaptation efforts involving resettlement programs. Informal settlements in Manila, Philippines, for example, were blamed for clogging drainage networks during devastating flooding events in 2009 and 2012, prompting the relocation of thousands of informal households away from waterway embankments as part of an effort to upgrade the city's flood management infrastructure (Anguelovski et al., 2016). Acts of commission share features of the concept of entrenchment, which Sovacool et al. (2015) define as the process by which adaptation projects aggravate political, socioeconomic, or cultural inequities, contributing to the subsequent disempowerment of disadvantaged groups. Displacement of informal settlements in the name of adaptation represents a process of entrenchment that exacerbates existing inequities and reinforces the unequal distribution of power (Shi et al., 2016). Relocated communities in Manila continue to be exposed to environmental threats in resettlement sites, where they have fewer livelihood resources to cope with impacts (Anguelovski et al., 2016). While these poorer, often minority communities are relocated to higher risk areas through processes of entrenchment and acts of commission, wealthier, formal communities remain in place.

On the other hand, injustices of omission occur when the protection of wealthier communities or assets is prioritized over the protection of poorer or marginalized ones (Anguelovski et al., 2016). In New Orleans, for instance, power imbalances and social inequity between wealthier, whiter neighbourhoods, and lowerincome communities of colour have limited local efforts to upgrade urban infrastructure in ways that would better protect minority residents from climate risks (Anguelovski et al., 2016). Acts of omission often occur when adaptation is framed as a private responsibility rather than a public good or when planning processes exclude impacted communities. Such plans usually result in the protection of elite groups and economically valuable areas at the expense of low-income or minority neighbourhoods. Acts of omission resemble practices of exclusion, which occur when adaptation projects limit access to resources for some groups or marginalize 
certain populations in the decision-making process (Sovacool et al., 2015).

It should be noted that acts of commission and omission often occur as part of broader efforts to mainstream adaptation in national development planning. The links between development and adaptation-specifically the relationship between poverty and adaptive capacityhave resulted in efforts to address the two in an integrated way (Ayers et al., 2014; Sherman et al., 2016). A full discussion of mainstreaming adaptation in development is beyond the scope of this review, but it is worth noting that vulnerable populations are disproportionately exposed to the negative consequences of poorly planned adaptation strategies that do not take inequities related to income, education, race, ethnicity, gender, age, and (dis)ability into consideration (Byskov et al., 2019). Further, retrofitting adaptation into existing development agendas-either by rebranding existing development activities as adaptation or co-opting new adaptation programs to support existing development agendas-risks maladaptation that inadvertently reinforces, redistributes, or creates new sources of vulnerability at the urban scale (Eriksen et al., 2021). Accordingly, there is concern about whether and how adaptation may be introducing new forms of vulnerability for some people and places, and about the equity dimensions of these potential redistributive effects (Atteridge \& Remling, 2017).

\subsection{Distributive, Procedural, and Recognition Justice}

Recognizing that disadvantaged populations suffer from injustices of commission and omission in the context of climate change, the justice of climate action planning is traditionally understood as a trilogy of procedural, distributive, and recognition justices. These dimensions of justice have been variably defined in the climate justice literature, highlighting the deeply contested and contextdependent nature of ideas of fairness and justice (Shi et al., 2016). Although these terms continue to be negotiated in the context of conflicting views and interests, distributive justice is generally understood to concern the allocation of benefits and burdens among multiple stakeholders, while procedural justice is concerned with fair, transparent, and inclusive decision-making (Grasso, 2007; Paavola \& Adger, 2006). Procedurally just planning enables meaningful and representative participation during the plan development and implementation process: This dimension of justice complements distributive justice by focusing on process rather than outcome, taking into account the power and participation disadvantages of marginalized groups. Although these complementary forms of justice are closely related, they are not necessarily automatically addressed together. Recognition justice emerges in the context of policy framing and analysis and considers how particular populations are made visible or invisible in policy development contexts. This dimension of justice is concerned with determining who is considered a relevant stakeholder, and which needs are included in climate-related decision-making frameworks (Klinsky \& Mavrogianni, 2020). Klinsky and Mavrogianni (2020) suggest that a multivalent approach to justice that includes distributive, procedural, and recognition justice concerns may be a useful way to integrate lines of analysis within the climate justice discourse. A multivalent framework also supports a transition from observations of inequities to analysis of why these occurred and how they could be addressed by decision-making processes (Klinsky \& Mavrogianni, 2020). Although a multivalent approach to justice has been used in climate-related contexts-such as the analysis of climate change mitigation policy (Klinsky, 2015) - much climate change adaptation planning has been predominately focused on achieving distributive justice (Bulkeley et al., 2013).

One of the key challenges in the application of procedural and recognition justice is ambiguity surrounding the concept of vulnerability (van den Berg \& Keenan, 2019). Our understanding of what it means to be vulnerable partly depends on the emphasis placed on various dimensions of risk and vulnerability. Variables such as exposure, sensitivity to risk, and capacity to cope determine the extent to which populations are adversely affected by climate risks (Garschagen \& Romero-Lankao, 2015), and as such, these variables inform our definition of what it means to be vulnerable. Our limited understanding of vulnerability is evidenced by vulnerability assessments that often do not adequately capture the social and political processes and relations that marginalize specific groups and determine how vulnerability is distributed across an urban population (Eriksen et al., 2021). Our understanding of vulnerability directly influences our definition of disadvantage in the context of climate change, which has important implications for determining who should be targeted by vulnerability-reducing interventions. Adaptation planning processes can privilege or undermine participation of certain groups by redefining what it means to be vulnerable and who is included in such definitions (Anguelovski et al., 2016), highlighting the need for variability and dynamism in the framing of vulnerability to ensure a full range of affected groups are represented. As climate change continues to shift the dynamics and distribution of inequity and risk, we need to adopt a flexible understanding of who is likely the most vulnerable and focus more attention on the potential for adaptation to inadvertently redistribute vulnerability (Atteridge \& Remling, 2017).

\section{Social Inequity as a Determinant of Adaptive Capacity}

The previous sections of this review have established that there is a direct connection between underlying social inequity and the likelihood of being adversely affected by climate change impacts. The social, economic, and political inequities that shape local vulnerabilities also influence adaptive capacity: The ability to adapt 
is thus enabled and constrained by the broader conditions influencing the vulnerability of a specific population. Eakin et al. (2014) understand adaptive capacity as being composed of two dimensions: generic and specific capacities. Generic capacities are associated with basic human development needs (e.g., health, education, economic security), while specific capacities are those necessary for managing and reducing specific climate threats. The interaction between generic and specific capacities has implications for levels of current vulnerability and the ability to adapt to future change: Populations with high generic and high specific capacities are most likely to achieve transformative adaptation outcomes that reduce overall vulnerability. While these two dimensions of adaptive capacity must be addressed explicitly and simultaneously to achieve adaptation goals, the degree of concerted attention each dimension requires depends on social and geographic context (Eakin et al., 2014). Previous research investigating the generic and specific determinants of adaptive capacity have repeatedly found economic resources to be a key driver of the ability to cope with climate risks (Brooks et al., 2005; Sayers et al., 2018; Smit et al., 2001). On the global scale, it is widely accepted that wealthier nations are better prepared to bear the costs of adaptation than poorer nations given the relationship between poverty and vulnerability. It has also been established that disadvantaged groups within nations are especially vulnerable to climate change because they are often more exposed to climate threats and have limited access to vulnerabilityreducing resources and emergency services (Long \& Rice, 2019, Smit et al., 2001).

Enhanced adaptive capacity is a practical means of coping with changes and uncertainties in climate and is a necessary condition for reducing vulnerability at the urban level. However, the socioeconomic characteristics of urban populations compound the justice and equity issues inherent in local climate change planning processes to create barriers to enhanced adaptive capacity. Inequities exist between cities in terms of their capacity and resources to plan for and respond to climate change, and between residents in terms of their ability to participate in planning processes (Chu \& Michael, 2019; Shi et al., 2016). While the latter can often be attributed to inequities in economic, social, and political power, the former is primarily influenced by time and resource constraints (Byskov et al., 2019). Studies in Canada have found that larger urban areas are more apt to be engaged in some form of adaptation planning because they benefit from greater access to resources and planning capacities (Hanna et al., 2014). Within cities, the uneven distribution of adaptive capacity creates areas of higher exposure to climate impacts on one hand, and areas of relative protection from these impacts on the other (Shi et al., 2016). Unless these disparities between and within cities are addressed, adaptation efforts may reinforce patterns of urban inequity. Accordingly, there is a need to critically assess the equity and inclusiveness of climate change adaptation planning both in terms of process and outcomes (Meerow \& Mitchell, 2017). The following section provides the necessary background for such an assessment by mapping the general landscape of climate change adaptation planning in the context of equity.

\section{The Current State of Climate Change Adaptation Planning in the Context of Equity}

The research findings reviewed in the previous sections have revealed that socioeconomic conditions determine vulnerability, which subsequently influences adaptive capacity. Findings also indicate that for adaptation efforts to be effective and socially accepted, they must strive to advance distributive, procedural, and recognition justice goals. These findings have important implications for effective climate change adaptation planning, yet the degree to which equity considerations are integrated into climate action plans remains under-researched. Despite growing efforts to mainstream climate change adaptation at the local level, it remains unclear whether adaptation efforts are helping to resolve inequities (Anguelovski et al., 2016), and "very little research has examined the actual distributive outcomes of ongoing and proposed adaptation interventions on the ground" (Shi et al., 2016, p. 132). There is also ongoing debate among scholars about the degree to which reactive versus anticipatory adaptation actions exacerbate or reduce vulnerabilities, although the details of that debate are beyond the scope of this review.

\subsection{Procedural Justice in Climate Change Adaptation Planning}

In cases where issues of equity and justice are considered, studies predominately focus on distributive justice, or the outcomes of adaptation processes. Consequently, procedural justice, or fairness in the process of planning climate change adaptation efforts, is often overlooked (van den Berg \& Keenan, 2019). Building equity into adaptation efforts hinges on the capacity of actors from marginalized communities to engage and actively participate in local adaptation planning efforts (Schrock et al., 2015). Thus, enhancing the procedural justice of adaptation planning practice calls for broader and more meaningful participation of marginalized groups. Recognizing this reality-and given the fact that procedural justice receives less attention from planners than distributive justice concerns - the remainder of this section focuses on procedural justice and equity in planning processes.

Planners generally agree on the importance of broad participation in policy responses to climate change, and calls for public participation in the development of adaptive responses are prominent in major policy documents on climate change that guide urban adaptation (notably the United Nations Framework Convention on Climate Change and the Third Assessment Report of the Intergovernmental Panel on Climate Change). The merits 
of community engagement in planning processes are also widely recognized, including increased quality and legitimacy of decisions (Paavola \& Adger, 2006; van den Berg \& Keenan, 2019) and generating buy-in from community members which aids in plan implementation (Guyadeen et al., 2019). Byskov et al. (2019) further argue that there are moral and knowledge-based reasons for including civil society actors in adaptation planning processes: Vulnerable communities possess valuable knowledge about local conditions that informs effective adaptation, and these populations have a right to influence the development of adaptation plans that affect them. Although cities often reference inclusion in their adaptation planning documents (Chu \& Cannon, 2021), this consideration appears surface-level given several studies that have concluded there is room to improve procedural equity in actual decision-making processes. For example, a recent survey of municipal climate change plans in 63 of the most populous communities across Canada found that only $40 \%$ of plans identified public participation as part of the plan creation process, and only $35 \%$ discussed the purpose of broader participation at all (Guyadeen et al., 2019). These findings are consistent with previous plan quality studies that have found limited evidence of stakeholder engagement or public participation during plan development (Baker et al., 2012; Fu et al., 2017). These studies reveal that despite the importance scholars and practitioners ascribe to public participation, cities often overlook this element of the climate change planning process.

One reason for this oversight may be the tension between the urgent need for adaptation and the resource- and time-demanding processes required by justice ideals (Byskov et al., 2019). Procedural injustice may also be attributed to the apparent tradeoff between broadly inclusive planning processes and long-term program stability. A comparison of inclusive approaches to urban climate change adaptation planning by Chu et al. (2016) revealed that in Quito, Ecuador, broad-based participatory planning approaches that engage citizens and affected communities have led to equally broad adaptation plans that lack specificity in how adaptation interventions are to be implemented, financed, and politically sustained. In contrast, adaptation planning approaches in Surat, India, which feature procedural justice considerations less prominently and instead emphasize strategic partnerships between key government, private, and civil society actors, have supported the implementation of durable adaptation projects but denied voice to vulnerable groups (Chu et al., 2016). While the latter approach appears more likely to ensure long-term program stability, this approach also confines decision-making responsibilities to a few elite community leaders and restricts the representation of marginalized groups in future programs and plans. These findings highlight an apparent trade-off between procedural justice considerations that ensure equity and justice outcomes in the short-term, and long-term viability of adaptation agendas. This is a trade-off that climate change adaptation planning is yet to fully eliminate.

\subsection{Plan Quality in the Context of Equity}

Plan quality measures the extent of the presence or absence of key components within a plan and has become an established framework for assessing the strengths and deficiencies of plans. Plan quality literature highlights eight commonly referenced characteristics that researchers have used to assess various types of plans across different scales. These characteristics focus on both the content and procedural aspects of plans and reflect consensus among researchers regarding the baseline characteristics that comprise high quality plans (Guyadeen et al., 2019). These characteristics include: 1) fact base; 2) goals; 3) policies; 4) implementation; 5) monitoring and evaluation; 6) inter-organizational coordination; 7) participation; and 8) plan organization and presentation. The participation characteristic is especially relevant for advancing equity in climate change plans because it focuses on how various groups are engaged and represented during the plan creation process. As such, the remainder of this section focuses on the participation characteristic.

Participatory planning processes serve to give voice to local concerns regarding the adverse impacts of climate change and help identify demographics that are particularly vulnerable to these impacts. Amplifying the voices of the most vulnerable during participatory decision-making processes grounds adaptation interventions in a sound understanding of vulnerability and increases the likelihood that the priorities and needs of vulnerable populations will be incorporated into policy (Byskov et al., 2019; Forsyth, 2018). Local patterns of vulnerability are dynamic: The relative importance of indicators such as age, race, ethnicity, and gender changes over time (Kashem et al., 2016; Thomas et al., 2018). Therefore, to maximize the procedural fairness of adaptation planning for the benefit of vulnerable populations, van den Berg and Keenan (2019) argue two things must be done. First, we must develop our capacity to frame and measure vulnerability in dynamic terms, and second, we must acknowledge, engage, and provide representation to vulnerable populations. Intentional inclusion and representation of marginalized groups are key elements of Sandercock's (2009) conception of the right to the city; that is, the right to presence, to occupy public space, and to participate as an equal in public affairs. The argument for prioritizing these aspects of the participation process is self-evident: To have meaningful participatory engagement, planners need to know who to engage with (hence the emphasis placed on improving our understanding of vulnerability). Moreover, an intervention that is successful for one individual may not be considered successful by another, highlighting the need for recognition and representation of vulnerable populations' range of interests, needs, and priorities during 
the planning process. Conversely, lack of meaningful public engagement and recognition of marginalized communities' development visions exacerbates procedural and recognition justice concerns and increases distrust in local plans.

Beyond participatory planning processes, efforts to adapt should promote more transformative solutions that deliberately address underlying drivers of vulnerability and forms of socio-spatial inequity (Pelling et al., 2015). Yet, cities in the Global North and South appear to overlook social equity considerations relative to environmental and economic imperatives (Schrock et al., 2015). Indeed, growing evidence suggests policy priorities are being oriented toward an "increasing focus on strategically important environmental resources and assets and the weakening of the commitment to comprehensive approaches and concerns with social justice and equity" (Hodson \& Marvin, 2017, p. 13). This trend may be a result of the perceived urgency for the adoption of climate action plans or the prioritization of neoliberal economic interests at the expense of social concerns (Trencher, 2019). In any case, overlooking social equity has the harmful effect of exacerbating existing urban inequities and providing new avenues for injustice (Intergovernmental Panel on Climate Change, 2014; Webber, 2016). Specifically, lack of attention to equity concerns leads to the absence of key participants who advocate for the interests of disadvantaged groups during the planning process. In turn, adaptive capacity in the most vulnerable communities remains inadequate. Pursuing transformative adaptation actions that are rooted in justice and equity considerations requires cities to more closely critique the plans and policies that have historically contributed to unequal access to resources. Planners must also pay more explicit attention to the distributive, procedural, and recognition justice implications of adaptation planning to avoid aggravating the vulnerability of disadvantaged groups.

\section{Conclusions}

This review has drawn on climate justice literature to establish the direct connection between social inequity and climate change impacts, and to clarify the ways equity and justice issues materialize in adaptation planning. Exploring various conceptions of disadvantage and vulnerability enhances our understanding of who is truly vulnerable in the context of climate change-knowledge we need to plan adaptation interventions that reduce rather than aggravate inequity. Findings from studies of climate change adaptation planning approaches in cities in the Global North and South reveal that adaptation planning affects urban equity and justice regardless of development, political, and ecological context. Moreover, inequitable climate change adaptation interventions appear to exacerbate, redistribute, and create new forms of socio-spatial inequities across diverse urban contexts.
Research has revealed that the vulnerability of a given population depends on a complex set of drivers and interacting conditions that can also influence adaptive capacity. Improving our understanding of the constraints and opportunities for enhancing adaptive capacity is necessary to promote more transformative adaptation solutions that deliberately address underlying drivers of vulnerability. Economic and environmental benefits and costs are important criteria for assessing the quality of adaptation plans, but these considerations are not sufficient to determine the overall effectiveness of adaptation measures. Equity considerations are a necessary component of adaptation planning, but more research examining whether, and to what extent, urban adaptation plans prioritize social vulnerability is needed.

The research findings discussed throughout this review illuminate the ways in which adaptation planning favours certain privileged groups while simultaneously denying resources and voice to marginalized communities experiencing various forms of social inequity. These findings inform the identification of disadvantaged groups for whom underlying social inequity causes disproportionate suffering from the adverse effects of climate change. Directions for future research include investigation into whether climate change adaptation planning at various scales adequately considers the needs and priorities of disadvantaged populations, both in terms of process and outcomes. Further exploration of the debate about the degree to which reactive versus anticipatory adaptation actions exacerbate or reduce vulnerabilities would also be useful, as would further study of the relationship between socioeconomic variables and the ability to live a climate resilient lifestyle at the household level. Finally, future research should address the challenges and trade-offs of featuring justice and equity considerations prominently in urban adaptation planning while also ensuring long-term program stability.

Greater effort to understand the complexities of vulnerability is needed given the scope of the climate challenge and the various ways in which climate change negatively impacts community development, quality of life, and sustainability (Meerow \& Woodruff, 2020). As the number of cities engaging in climate change adaptation planning continues to grow, the quality of adaptation plans in terms of equity considerations should be more closely assessed. Researchers must consider whether adaptation efforts are effectively prioritizing the needs of marginalized and vulnerable populations, or whether they "merely re-package business-asusual [planning] approaches" (Anguelovski et al., 2016, p. 332) that have historically excluded marginalized voices and made disadvantaged groups more vulnerable. This review begins to lay the groundwork for research that responds to these concerns by providing context for critical assessment of adaptation plans from an equity perspective. 


\section{Acknowledgments}

The author would like to thank the reviewers for their constructive feedback.

\section{Conflict of Interests}

The author declares no conflict of interests.

\section{References}

Adger, W., Arnell, N., \& Tompkins, E. (2005). Successful adaptation to climate change across scales. Global Environmental Change, 15, 77-86.

Anguelovski, I., Shi, L., Chi, E., Gallagher, D., Goh, K., Lamb, Z., Reeves, K., \& Teicher, H. (2016). Equity impacts of urban land use planning for climate adaptation: Critical perspectives from the Global North and South. Journal of Planning Education and Research, 36(3), 333-348.

Atteridge, A., \& Remling, E. (2017). Is adaptation reducing vulnerability or redistributing it? Wiley Interdisciplinary Reviews: Climate Change, 9(1), Article e500. https://doi.org/10.1002/wcc.500

Ayers, J., Huq, S., Wright, H., Faisal, A. M., \& Hussain, S. T. (2014). Mainstreaming climate change adaptation into development in Bangladesh. Climate and Development, 6(4), 293-305.

Baker, I., Peterson, A., Brown, G., \& McAlpine, C. (2012). Local government response to the impacts of climate change: An evaluation of local climate adaptation plans. Landscape and Urban Planning, 107(2), 127-136.

Barnett, J. (2006). Climate change, insecurity, and injustice. In W. Adger, J. Paavola, S. Huq, \& M. Mace (Eds.), Fairness to adaptation to climate change (pp. 115-130). MIT Press.

Bathiany, S., Dakos, V., Scheffer, M., \& Lenton, T. (2018). Climate models predict increasing temperature variability in poor countries. Science Advances, 4(5), Article eaar5809.

Blake, R., Grimm, A., Ichinose, T., Horton, R., Gaffi, S., Jiong, S., Bader, D., \& Cecil, L. (2011). Urban climate: Processes, trends, and projections. In C. Rosenzweig, W. D. Solecki, S. A. Hammer, \& S. Mehrotra (Eds.), Climate change and cities: First assessment report of the urban climate change research network (pp. 43-81). Cambridge University Press.

Brooks, N., Adger, W., \& Kelly, M. (2005). The determinants of vulnerability and adaptive capacity at the national level and the implications for adaptation. Global Environmental Change, 15(2), 151-163.

Bulkeley, H., Carmin, J., Castan Broto, V., Edwards, G. A. S., \& Fuller, S. (2013). Climate justice and global cities: Mapping the emerging discourses. Global Environmental Change, 23(5), 31-40.

Byrnes, W. M. (2014). Climate justice, Hurricane Katrina, and African American environmentalism. Journal of
African American Studies, 18(3), 305-314.

Byskov, M. F., Hyams, K., Satyal, P., Anguelovski, I., Benjamin, L., Blackburn, S., Borie, M., Caney, S., Chu, E., Edwards, G., Fourie, K., Fraser, A., Heyward, C., Jeans, H., McQuistan, C., Paavola, J., Page, E., Pelling, M., Priest, S., \& Swiderska, K. (2019). An agenda for ethics and justice in adaptation to climate change. Climate and Development, 13, 1-9. https://doi.org/10.1080/ 17565529.2019.1700774

Canadian Institute of Planners. (2011). Climate change adaptation planning: A handbook for small Canadian communities. https://www.cip-icu.ca/Files/ Resources/RURAL-HANDBOOK-FINAL-COPY

Cardona, O.-D., van Aalst, M. K., Birkmann, J., Fordham, M., McGregor, G., Perez, R. S., Pulwarty, R. S., Schipper, E. L. F., \& Sinh, B. T. (2012). Determinants of risk: Exposure and vulnerability. In C. B. Field, V. Barros, T. M. Stocker., D. Qin, D. J. Dokken, K. L. Ebi, M. D. Mastrandrea, K. J. Mach, G.-K. Plattner, S. K. Allen, M. Tignor, \& P. M. Midgley (Eds.), Managing the risks of extreme events and disasters to advance climate change adaptation (pp. 65-108). Cambridge University Press.

Chu, E., Anguelovski, I., \& Carmin, J. (2016). Inclusive approaches to urban climate adaptation planning and implementation in the Global South. Climate Policy, 16(3), 372-392.

Chu, E., \& Cannon, C. (2021). Equity, inclusion, and justice as criteria for decision-making on climate adaptation in cities. Current Opinion in Environmental Sustainability, 51, 85-94.

Chu, E., \& Michael, K. (2019). Recognition in urban climate justice: Marginality and exclusion of migrants in Indian cities. Environment \& Urbanization, 31(1), 139-156.

Davoudi, S., Crawford, J., \& Mehmood, A. (2009). Planning for climate change: Strategies for mitigation and adaptation for spatial planners. Earthscan.

Eakin, H., Lemos, M., \& Nelson, D. (2014). Differentiating capacities as a means to sustainable climate change adaptation. Global Environmental Change, 27, 1-8.

Eriksen, S., Schipper, E. L. F., Scoville-Simonds, M., Vincent, K., Adam, H. N., Brooks, N., Harding, B., Khatri, D., Lenaerts, L., Liverman, D., Mills-Novoa, M., Mosberg, M., Movik, S., Muok, B., Nigtingale, A., Ojha, H., Sygna, L., Taylor, M., Vogel, C., \& West, J. J. (2021). Adaptation interventions and their effect on vulnerability in developing countries: Help, hindrance, or irrelevance? World Development, 141, Article 105383.

Forsyth, T. (2018). Is resilience to climate change socially inclusive? Investigating theories of change processes in Myanmar. World Development, 111, 13-26.

Fu, X., Gomaa, M., Deng, Y., \& Peng, Z. (2017). Adaptation planning for sea level rise: A study of US coastal cities. Journal of Environmental Planning and Management, 60(2), 249-265.

Garschagen, M., \& Romero-Lankao, P. (2015). Exploring 
the relationships between urbanization trends and climate change vulnerability. Climatic Change, 133, 37-52.

Graif, C. (2016). (Un)natural disaster: Vulnerability, longdistance displacement, and the extended geography of neighbourhood distress and attainment after Katrina. Population and Environment, 37, 288-318.

Grasso, M. (2007). A normative ethical framework in climate change. Climatic Change, 81, 223-246.

Guyadeen, D., Thistlethwaite, J., \& Henstra, D. (2019). Evaluating the quality of municipal climate change plans in Canada. Climate Change, 152(1), 121-243.

Hallegatte, S., Fay, M., \& Barbier, E. B. (2018). Poverty and climate change: Introduction. Environment and Development Economics, 23(3), 217-233.

Hallegatte, S., \& Rozenberg, J. (2017). Climate change through a poverty lens. Nature Climate Change, 7(4), 250-256.

Hanna, K., Seasons, M., Dale, A., Filion, P., \& Ling, C. (2014). Planning for climate change: The state of current practice in Canada. Plan Canada, 54(2), 28-36.

Hodson, M., \& Marvin, S. (2017). Intensifying or transforming sustainable cities? Fragmented logics of urban environmentalism. Local Environment, 22(Suppl. 1), 8-22.

Intergovernmental Panel on Climate Change. (2014). AR5 Climate change 2014: Impacts, adaptation and vulnerability. https://www.ipcc.ch/report/ar5/wg2

Islam, S., \& Winkel, J. (2017). Climate change and social inequality (Working Paper No. 152). Department of Economic \& Social Affairs. https://www.un.org/esa/ desa/papers/2017/wp152_2017.pdf

Jerneck, A., \& Olsson, L. (2008). Adaptation and the poor: Development, resilience and transition. Climate Policy, 8, 170-182.

Kashem, S. B., Wilson, B., \& Van Zandt, S. (2016). Planning for climate adaptation: Evaluating the changing patterns of social vulnerability and adaptation challenges in three coastal cities. Journal of Planning Education and Research, 36(3), 304-318.

Kelly, P., \& Adger, W. (2000). Theory and practice in assessing vulnerability to climate change and facilitating adaptation. Climate Change, 47, 325-352.

Klinsky, S. (2015). Justice and boundary setting in greenhouse gas cap and trade policy: A case study of the Western Climate Initiative. Annals of the Association of American Geographers, 105(1), 105-122.

Klinsky, S., \& Mavrogianni, A. (2020). Climate justice and the built environment. Buildings and Cities, 1(1), 412-428.

Klinsky, S., Roberts, T., Huq, S., Okereke, C., Newell, P., Dauvergne, P., O’Brien, K., Schroeder, H., Tschakert, P., Clapp, J., Keck, M., Biermann, F., Liverman, D., Gupta, J., Rahman, A., Messner, D., Pellow, D., \& Bauer, S. (2017). Why equity is fundamental in climate change policy research. Global Environmental Change, 44, 170-173.

Kunz, M. B., Mühr, T., Kunz-Plapp, J. E., Daniell, J. E.,
Khazai, B., Wenzel, F., Vannieuwenhuyse, M., Comes, T., Elmer, F., Schröter, K., Fohringer, J., Münzberg, T., Lucas, C., \& Zschau, J. (2013). Investigation of Superstorm Sandy 2012 in a multi-disciplinary approach. Natural Hazards and Earth System Sciences, 13, 2579-2598.

Long, J., \& Rice, J. (2019). From sustainable urbanism to climate urbanism. Urban Studies, 56(5), 992-1008.

Meerow, S., \& Mitchell, C. (2017). Weathering the storm: The politics of urban climate change adaptation planning. Environment and Planning A, 49(11), 2619-2627.

Meerow, S., \& Woodruff, S. (2020). Seven principles of strong climate change planning. Journal of the American Planning Association, 86(1), 39-46.

Paavola, J., \& Adger, W. (2006). Fair adaptation to climate change. Ecological Economics, 56(4), 594-609.

Pelling, M., O’Brien, K., \& Matyas, D. (2015). Adaptation and transformation. Climate Change, 133(1), 113-127.

Sandercock, L. (2009). When strangers become neighbours: Managing cities of difference. Planning Theory \& Practice, 1(1), 13-30.

Sayers, P., Penning-Rowsell, E. C., \& Horritt, M. (2018). Flood vulnerability, risk, and social disadvantage: Current and future patterns in the UK. Regional Environmental Change, 18(2), 339-352.

Schlosberg, D. (2013). Theorising environmental justice: The expanding sphere of a discourse. Environmental Politics, 22(1), 37-55.

Schrock, G., Bassett, E., \& Green, J. (2015). Pursuing equity and justice in a changing climate: Assessing equity in local climate and sustainability plans in US cities. Journal of Planning Education and Research, 35(3), 282-295.

Sherman, M., Berrang-Ford, L., Lwasa, S., Ford, J., Namanya, D. B., Llanos-Cuentas, A., Maillet, M., Harper, S., \& IHACC Research Team. (2016). Drawing the line between adaptation and development: A systematic literature review of planned adaptation in developing countries. Wiley Interdisciplinary Reviews: Climate Change, 7(5), 707-726. https://doi. org/10.1002/wcc.416

Shi, L., Chu, E., Anguelovski, I., Aylett, A., Debats, J., Goh, K., Schenk, T., Seto, K. C., Dodman, D., Roberts, D., Roberts, J. T., \& VanDeveer, S. D. (2016). Roadmap towards justice in urban climate adaptation research. Nature Climate Change, 6(2), 131-137.

Smit, B., Pilifosova, O., Burton, I., Challenger, B., Huq, S., Klein, R. J. T., Adger, N., Downing, T., Harvey, E., Kane, S., Skinner, M., Smith, J., \& Wandel, J. (2001). Adaptation to climate change in the context of sustainable development and equity. In J. J. McCarthy, O. F. Canziani, N. A. Leary, D. J. Dokken, \& K. S. White (Eds.), Climate change 2001: Impacts, adaptation, and vulnerability (pp. 877-912). Cambridge University Press.

Smit, B., \& Wandel, J. (2006). Adaptation, adaptive capac- 
ity and vulnerability. Global Environmental Change, 16, 282-292.

Sovacool, B., Linné, B., \& Goodsite, M. (2015). The political economy of climate adaptation. Nature Climate Change, 5(7), 616-618.

Steele, W., Maccallum, D., Byrne, J., \& Houston, D. (2012). Planning the climate-just city. International Planning Studies, 17(1), 67-83.

Thomas, K., Hardy, R. D., Lazrus, H., Mendez, M., Orlove, B., Rivera-Collazo, I., Roberts, J. T., Rockman, M., Warner, B. P., \& Winthrop, R. (2018). Explaining differential vulnerability to climate change: A social science review. Wiley Interdisciplinary Reviews: Climate Change, 10(2), Article e565. https://doi.org/ 10.1002/wcc.565

Trencher, G. (2019). Towards the smart city 2.0: Empir- ical evidence of using smartness as a tool for tackling social challenges. Technological Forecasting and Social Change, 142, 117-128.

United Nations Human Settlements Program. (2011). Cities and climate change: Global report on human settlements 2011. Earthscan.

van den Berg, H., \& Keenan, J. (2019). Dynamic vulnerability in the pursuit of just adaptation processes: A Boston case study. Environmental Science \& Policy, 94, 90-100.

Wamsler, C., Brink, E., \& Rivera, C. (2013). Planning for climate change in urban areas: From theory to practice. Journal of Cleaner Production, 50, 68-81.

Webber, S. (2016). Climate change adaptation as a growing development priority: Towards critical adaptation scholarship. Geography Compass, 10(10), 401-413.

\section{About the Author}

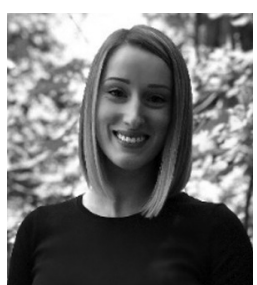

Kayleigh Swanson is a doctoral student in the School of Planning at the University of Waterloo. She has previously collaborated on research exploring climate compatible development strategies that reduce poverty and advance gender equality. Her current research considers the way equity and social justice considerations are articulated and embedded in climate action plans. 